\title{
Trends and determinants of HIV/AIDS knowledge among women in Bangladesh
}

Sanni Yaya ${ }^{1 *} \mathbb{D}$, Ghose Bishwajit², Georges Danhoundo ${ }^{2}, V^{2}$ aibhav Shah ${ }^{4}$ and Michael Ekholuenetale ${ }^{5}$

\begin{abstract}
Background: Globally, women share an indiscriminate burden of the HIV epidemic and the associated socioeconomic consequences. Previous studies have demonstrated a positive correlation between levels of HIV knowledge with its prevalence. However, for Bangladesh such evidence is non-existent. In this study, we aimed to explore the extent of HIV knowledge in relation to the socio-demographic variables such as age, region, area of residence i.e., urban or rural, wealth index and education, and investigate the factors influencing the level of HIV knowledge among Bangladeshi women.

Methods: We used data from the Bangladesh Demographic and Health Survey (BDHS) survey conducted in 2011. In total 12,512 women ageing between 15 and 49 ever hearing about HIV regardless of HIV status were selected for this study. HIV knowledge level was estimated by analyzing respondents' answers to a set of 11 basic questions indicative of general awareness and mode of transmission. Descriptive statistics, cross-tabulation and multinominal logistic regression were performed for data analysis.

Results: Little over half the respondents had good knowledge regarding HIV transmission risks. The mean HIV knowledge score was -0.001 (SD 0.914). Average correct response rate about mode of transmission was higher than for general awareness. Educational level of women and sex of household head were found to be significantly associated with HIV knowledge in the high score group. Those with no education, primary education or secondary education were less likely to be in the high score group for HIV knowledge when compared with those with higher than secondary level of education. Similarly those with male as household head were less likely to be in the higher score group for HIV knowledge.

Conclusions: Level of HIV knowledge among Bangladeshi women is quite low, and the limiting factors are rooted in various demographic and household characteristics. Education and sex of the household head have been found to be significantly correlated with the level of HIV knowledge and propound sound grounds for their incorporation in the future HIV prevention strategies. Education of women may also have wider ramifications allowing reduction in gender inequality, which in turn favors higher knowledge about HIV.
\end{abstract}

Keywords: HIV knowledge, Women health, Global health, Bangladesh, Demographic and health survey

Abbreviations: BRDB, Bangladesh rural development board; DHS, Demographic and health survey; HIV, Human immunodeficiency virus; STDs, Sexually transmitted diseases

\footnotetext{
* Correspondence: sanni.yaya@uOttawa.ca

${ }^{1}$ School of International Development and Global Studies, Faculty of Social

Sciences, University of Ottawa, Ottawa, ON, Canada

Full list of author information is available at the end of the article
} 


\section{Background}

Women in Bangladesh, similar to the current global trend, share a greater risk of HIV infection and mortality compared to men [1]. As per 2012 UNICEF estimates, the prevalence (per 10,000) of HIV among women Bangladeshi was 2.7 against total prevalence of 3.1. Apart from greater risk of susceptibility, the consequence of the disease also has a heavier onus on women owing to their less advantaged socioeconomic standing and lack of physical and social access to quality care especially sexually and reproductive health (SRH). There is a growing consensus on the fact that gender inequality is a great contributor to women's increased susceptibility to HIV morbidity and its consequences [2-5]. Not surprisingly, the gender aspect of this disease has been able to draw considerable attention in high level international events.

The 2001 United Nations General Assembly Special Session on HIV/AIDS (UNGASS) declaration marked a renewed call for strengthening policy capacities to address the gender issues related to HIV [6]. The problem is complex and exerts a huge toll on not only woman and her children/household, but also retards national progress at large. The negative impacts of gender inequality on HIV prevention efforts are felt even in developed countries [7] despite the greater socioeconomic freedom among women and presence of gender sensitive health and social policies. The major hurdle for such accomplishments in developing countries, like in Bangladesh, is the lack of recognition of the problem and of infrastructural capacity to conduct quality research and thereby identifying the issues that underlie the problem. Development and advancement of gender and health promotion policies are contingent primarily upon availability of workable insights in which Bangladesh lags significantly behind than expected.

The scientific literature on gender aspects of HIV suggests that the root goes deep into the sociocultural value system [8], and is generally attributed to values and perception regarding health and disease especially adult health issues and cultural context of women's role in the family and society [9, 10]. Level of knowledge of adult and reproductive health, including STDs tend to be higher in societies where people enjoy greater degree in freedom of communication, seek health advocacy, and engage in peer communication [11-13]. Policies that encourage such advantages would contribute to improvement of HIV knowledge among women especially in developing countries where women have little exposure to modern communication tools.

Given the rapid expansion of electronic media and social networking, the social barrier to knowledge improvement regarding STDs is shrinking [14-16], however physical access requires more pertinent policy approaches. In Bangladesh, mobile and internet subscription rate have increased substantially in last two decades. One study encompassing information from 137 countries figured that the gender gap on HIV knowledge has been narrowing; however, knowledge regarding preventive techniques is still low [17]. The same study reported that among people aged 15-24; the rate of comprehensive knowledge about HIV prevention was lower among women compared to men (36\% among women vs $40 \%$ among men) [17].

Despite the well-acknowledged gender aspects of the epidemic, and the possibility of spread of HIV epidemic, more extensive and strategic efforts to promote knowledge and awareness regarding HIV among women in Bangladesh are warranted. Given the relatively low HIV morbidity and mortality rate in Bangladesh, which is similar to other the South Asian countries, there seems to be an apparent oversight of the possibility of its future expansion. Since the first HIV case recognition in the country in 1986, some 9000 people are reported to living with HIV presently. However, it should be noted that though the disease burden is still low, the possibility of spread remains quite high due to widespread prevalence the risk factors [18-20]. The main concerns for HIV transmission in Bangladesh includes high rate of commercial sex, poor blood screening facilities, injection drug use, increasing rate of MSM, all of which deserve serious concerns in their own merit [21-24].

Studies have found that these factors themselves are more prevalent in societies with higher rate of poverty, illiteracy and gender inequality, which are the characteristic of the current situation in Bangladesh [24-27]. Previous studies reported low level of knowledge and awareness regarding STDs among Bangladeshi women [17]. From the perspective of its ease of transmission, level of personal knowledge and awareness are crucial elements for prevention of transmission irrespective of the performance of the healthcare system. Lack of knowledge is usually associated with stigma and leads to poor health seeking behavior, and thus increases the chances of going undiagnosed [28-30]. In Bangladesh, community based knowledge and awareness programs have proven successful in the areas of reducing maternal and tuberculosis mortality. Since women share greater vulnerability to HIV, increasing HIV knowledge among women offers potential opportunities for long-term controlling of the epidemic in Bangladesh. In this study, we aimed to explore the factors associated with the level of HIV knowledge.

Advances in HIV research are attributed to biological, clinical science. However, attention to behavioral risk factors offers the opportunity to explore avenues for intervention development. The future direction of this pandemic depends on the level of knowledge of how the virus is spread and changes in sexual behavior and attitudes. Accordingly, this study aims to explore the impact 
of socidemographic and household variables on the degree of HIV knowledge among women. Unlike other studies focusing on the clinical aspect of HIV, this paper focuses on the social factors, which could be targeted toward future prevention strategies. The paper being one of the few known population based studies on the subject of HIV knowledge and social factors heralds the research on the topic for future studies as well.

\section{Methods}

\section{Ethical clearance}

The DHS Program maintains strict standards for protecting the privacy of all participants. Before each interview, interviewers read out an informed consent statement and mentioned that participation is voluntary and respondent has the liberty to terminate the interview at any point. In addition, the ICF International ensures that the survey complies with the U.S. Department of Health and Human Services regulations for the protection of human subjects, and the host country ensures that the survey complies with laws and norms of the nation [23]. Approval for this study was not required since the data is secondary and is available in the public domain. More details regarding DHS data and ethical standards are available at: http://goo.gl/ny8T6X.

\section{Data source, study area, and sampling procedure}

Data for this study were sourced from the sixth round (latest) of Bangladesh Demographic and Health survey (BDHS). The DHS survey is nationally representative, cross-sectional in nature, and was carried out in 2011 from July 8 through December 27. The National Institute of Population Research and Training (NIPORT), a renowned health research organization in Bangladesh, conducted the survey. The survey is a part of the International Demographic and Health Survey program known as MEASURE DHS, which is currently active in 90 countries, and conducted under the auspices of the United State Agency for International Development (USAID) and technical assistance of ICF International of Calverton based in USA. BDHS 2011 covered in total 17,141 households.

The survey employed a two-stage cluster sampling method covering the population residing in noninstitutional dwelling units in Bangladesh. The country has seven administrative regions, which are subdivided into zilas (districts) and upazilas (townships). At urban level, an upazila is divided into union parishads and mouzas (subdivision of union parishads), and at rural level into wards and mohallas (subdivision of wards). The two-stage clustering of the population involved labelling the smallest administrative units as enumeration areas (EAs) or clusters, each consisting of households at mouza or mohalla level. Firstly, 600 EAs were selected based on their size proportional to that of the units. Of these 600 EAs 393 belonged to the rural areas whereas 207 were from urban areas. A complete listing of housing was done for the selected EAs. In the second stage, households were selected from each EA to ensure effective sampling with an average of 30 households from each EA. A total of 18,000 households were selected for the survey with the expectation of interviewing 18,000 women in the age range of 15-49 years. DHS provides no exact information on the spatial dimension of EAs. However, it consists about hundred to 30 thousand households varying from country to country.

\section{Variables selection and measurement}

The dependent variable in this study was level of HIV Knowledge. A set of 11 questions pertinent to HIV knowledge was selected from DHS questionnaire to which respondents could answer: yes/no/don't know. Categorical Principal Component analysis was conducted and the variables were quantified and produced object scores for each individual case. With all the component loadings being positive the object scores identified the performance of each individual case in the given domain.

Object scores were calculated using Categorical PCA, which were then ranked into tertiles i.e., Low, Medium and High score on the dimension of HIV knowledge with 3 designating low, 2 medium and 1 as high score.

To facilitate the selection of relevant covariates in the context of HIV knowledge, an extensive literature review was conducted focusing on two most proximate themes: demographic and household status. Based on the availability of variables in the dataset, the following items were selected for analysis: Age, Region, Type of residency i.e., Urban or Rural, Educational Level and Household wealth index.

Respondents' age in five year groups was used a categorical variable. Type of residency was categorized as rural and urban. Educational status was categorized as having no education, primary education, secondary education and those having higher education. We also included household wealth index in our analysis as it has been shown to be a reliable indicator of household economic condition impacting overall living and health status. DHS surveys assign five different levels based on overall income and wealth status as: poorest, poorer, middle, richer, richest.

\section{Data analysis}

Frequencies and percentages were measured for the questions used in assessing HIV knowledge among participants. Socio-demographic characteristics were tabled using descriptive statistics. Cross tabulation and $\chi^{2}$ test were performed for associated probabilities and to check 
for statistical association between groups based on HIV knowledge score (object score). Response variable was divided into tertiles with ties to the mean, as those with high score, medium score or low score. Given the nature of the dependent variable, we used multinomial logistic regression analysis to adjust for potential confounders and examine the independent effect of the explanatory variables on HIV knowledge status. At this level, only the variables, which were found to have significant association from cross-tabulation, were entered into regression model. Odds ratios were measured to assess the likelihood of having high, medium or low score on HIV knowledge among groups with particular socioeconomic and other characteristics. Results of regression analysis are presented as $p$-values and odds ratios. Level of statistical significance was set at $p<0.05$ (two-tailed). All analyses were performed using SPSS version 21.0 for Windows (SPSS Inc. Chicago. IL. USA).

\section{Results}

\section{Level of HIV Knowledge}

Levels of HIV knowledge are shown in Table 1. Composite level of HIV knowledge i.e., HIV score, was calculated by quantifying the categorical variables measuring HIV knowledge. The mean HIV knowledge score was -0.001 (SD 0.914). HIV knowledge was divided into tertiles with $33.1 \%$ in the high score tertile, $41.9 \%$ in the medium score tertile and $25 \%$ in the low score tertile. The correct response rate about mode of transmission was higher than for general awareness. Percentage of correct answers for individual questions is presented in Table 2 . Nearly two-third $(70.1 \%)$ of the respondents reported

Table 1 Percentage of correct answers by questions among women who reported ever hearing about HIV

\begin{tabular}{lc}
\hline Questions & $\begin{array}{l}\text { Percentage of correct } \\
\text { answers }\end{array}$ \\
\hline $\begin{array}{l}\text { Reduce risk of getting HIV: always use } \\
\text { condoms during sex }\end{array}$ & 64.1 \\
$\begin{array}{l}\text { Reduce risk of getting HIV: have one } \\
\text { sex partner only, who has no other partners }\end{array}$ & 74.0 \\
A healthy looking person can have HIV & 71.3 \\
HIV transmitted during pregnancy & 85.4 \\
HIV transmitted during delivery & 70.3 \\
HIV transmitted by breastfeeding & 81.3 \\
Can get HIV from mosquito bites & 47.3 \\
Can get HIV by sharing food with person & 55.6 \\
who has AIDS & \\
Can get HIV by witchcraft or supernatural \\
means \\
$\begin{array}{l}\text { Can get HIV by using unsterilized needle } \\
\text { or syringe }\end{array}$ \\
$\begin{array}{l}\text { Can get HIV through unsafe blood } \\
\text { transfusion }\end{array}$
\end{tabular}

Table 2 Socio-demographic characteristics of the participants $(n=12512)$

\begin{tabular}{|c|c|c|}
\hline Variable & Frequency & Percent \\
\hline \multicolumn{3}{|l|}{ Age } \\
\hline $15-19$ & 1441 & $11.5 \%$ \\
\hline $20-24$ & 2724 & $21.8 \%$ \\
\hline $25-29$ & 2562 & $20.5 \%$ \\
\hline $30-34$ & 1912 & $15.3 \%$ \\
\hline $35-39$ & 1524 & $12.2 \%$ \\
\hline $40-44$ & 1292 & $10.3 \%$ \\
\hline $45-49$ & 1001 & $8.0 \%$ \\
\hline \multicolumn{3}{|l|}{ Residency } \\
\hline Urban & 5182 & $41.4 \%$ \\
\hline Rural & 7330 & $58.6 \%$ \\
\hline \multicolumn{3}{|c|}{ Educational attainment } \\
\hline Nil & 1880 & $15.0 \%$ \\
\hline Primary & 3418 & $27.3 \%$ \\
\hline Secondary & 5754 & $46.0 \%$ \\
\hline Higher & 1460 & $11.7 \%$ \\
\hline \multicolumn{3}{|l|}{ Region } \\
\hline Barisal & 1521 & $12.2 \%$ \\
\hline Chittagong & 2028 & $16.2 \%$ \\
\hline Dhaka & 2335 & $18.7 \%$ \\
\hline Khulna & 2157 & $17.2 \%$ \\
\hline Rajshahi & 1727 & $13.8 \%$ \\
\hline Rangpur & 1445 & $11.5 \%$ \\
\hline Sylhet & 1299 & $10.4 \%$ \\
\hline
\end{tabular}

ever hearing about HIV and of those two third $74 \%$ knew that having one sex partner reduces risk of getting HIV. About two-third women knew that condoms could help prevent sexual transmission of HIV. Only about $70 \%$ women knew that HIV could be transmitted during delivery. Over $80 \%$ answered correctly about HIV transmission risks during pregnancy and breastfeeding. About $22 \%$ of the respondents believed that HIV could be caused by means of witchcraft or supernatural powers. Over $90 \%$ knew that using unsterilized needle or syringe and unsafe blood transfusion increases the risk of HIV infection. Lowest correct response was for the questions of whether or not transmission can happen through mosquito bite and sharing food with persons who has HIV (47.3 and $55.6 \%$ respectively).

\section{Socio-demographic characteristics of the sample population}

Socio-demographic characteristics of the sample population are shown in Table 2. Two-third of the participants $(65.3 \%)$ were of rural origin and almost a quarter $(26 \%)$ had no formal education. About one-third (29.9 \%) of the 
participants had completed primary education and $35.9 \%$ had completed secondary level of education. Only about $8 \%(8.2 \%)$ had higher than secondary level of education. About $90 \%$ were from male-headed households. Participants were fairly equitably distributed in the various regions of the country with the top three regions in terms of frequency of participants being from Dhaka followed by Khulna and Chittagong.

Results of cross-tabulation are presented in Table 3 showing the comparison between participants in groups based on their HIV knowledge score in relation to sociodemographic variables (Age, residency, education, region) and household variable (wealth index). Results indicate that household factor i.e., wealth index was significantly associated with level of HIV knowledge. Participants' age was not a significant factor. Region of residence, type of residence and sex of household head were all significantly associated with level of HIV knowledge. Apart from participants age; owning a mobile phone, literacy status, belonging to mother's club, and being aware of community clinic were found to be insignificant and were eliminated from subsequent analysis.

\section{Factors affecting level of HIV knowledge}

Factors influencing HIV knowledge among women are shown in Table 4. Based on the result of chi-square test of association, the following variables were found to be significantly associated with the outcome variable and were entered in the regression model: sex of household head, wealth index, education level, region and type of residence. Age of the respondent although not significantly associated, was entered as an independent variable to understand the impact of individual age ranges on HIV knowledge. Women from male-headed families were 0.756 times less likely to have higher score on HIV knowledge as compared to low score. Household wealth was also positively correlated with HIV knowledge level. Women from all the four wealth index quintiles ranging from poorest to richer quintiles were less likely to be in higher score group for HIV knowledge as compared to low score group, compared to richest wealth index quintile. The respective odds ratio for the same were 0.901, $0.763,0.941$ and 0.949 , respectively.. Education was strongly associated with HIV knowledge. Those who had education of secondary or less were consistently less likely to be in the higher score group compared to low score group of HIV knowledge when compared with those who had higher than secondary level of education. Previous studies have highlighted the import of education and gender inequity, which resonates, with the findings of the current study [31]. Similarly, region of residence was another variable associated with HIV knowledge. Although, all the regions were not significantly associated with HIV knowledge, Barisal and Khulna consistently were more
Table 3 Factors correlated with level of HIV knowledge

\begin{tabular}{|c|c|c|c|c|c|}
\hline & \multicolumn{3}{|c|}{ HIV Knowledge Score } & \multirow{2}{*}{$\begin{array}{l}\text { Chi } \\
\text { square }\end{array}$} & \multirow[t]{2}{*}{$p$ value } \\
\hline & $\begin{array}{l}\text { High } \\
\text { Score }\end{array}$ & $\begin{array}{l}\text { Medium } \\
\text { Score }\end{array}$ & $\begin{array}{l}\text { Low } \\
\text { Score }\end{array}$ & & \\
\hline \multicolumn{6}{|l|}{ Age } \\
\hline $15-19$ years & $5.2 \%$ & $1.9 \%$ & $4.4 \%$ & 17.549 & 0.130 \\
\hline 20-24 years & $10.1 \%$ & $3.7 \%$ & $8.1 \%$ & & \\
\hline $25-29$ years & $9.7 \%$ & $3.6 \%$ & $7.3 \%$ & & \\
\hline 30-34 years & $7.6 \%$ & $2.7 \%$ & $5.0 \%$ & & \\
\hline $35-39$ years & $6.0 \%$ & $2.0 \%$ & $4.2 \%$ & & \\
\hline 40-44 years & $4.9 \%$ & $1.8 \%$ & $3.6 \%$ & & \\
\hline 45-49 years & $3.7 \%$ & $1.4 \%$ & $2.9 \%$ & & \\
\hline \multicolumn{6}{|l|}{ Wealth Index } \\
\hline Poorest & $4.5 \%$ & $2.0 \%$ & $4.1 \%$ & 72.757 & $<0.0001^{*}$ \\
\hline Poor & $6.1 \%$ & $2.3 \%$ & $6.0 \%$ & & \\
\hline Middle & $8.9 \%$ & $3.5 \%$ & $6.8 \%$ & & \\
\hline Rich & $11.8 \%$ & $4.0 \%$ & $8.7 \%$ & & \\
\hline Richest & $15.9 \%$ & $5.3 \%$ & $10.0 \%$ & & \\
\hline \multicolumn{6}{|l|}{ Highest Education } \\
\hline No Education & $5.7 \%$ & $2.8 \%$ & $6.5 \%$ & 159.963 & $<0.0001^{*}$ \\
\hline Primary & $12.1 \%$ & $4.8 \%$ & $10.4 \%$ & & \\
\hline Secondary & $22.7 \%$ & $7.8 \%$ & $15.5 \%$ & & \\
\hline Higher & $6.8 \%$ & $1.6 \%$ & $3.3 \%$ & & \\
\hline \multicolumn{6}{|l|}{ Region } \\
\hline Barisal & $6.8 \%$ & $1.8 \%$ & $3.5 \%$ & 85.210 & $<0.0001^{*}$ \\
\hline Chittagong & $7.2 \%$ & $2.7 \%$ & $6.2 \%$ & & \\
\hline Dhaka & $8.4 \%$ & $3.5 \%$ & $6.8 \%$ & & \\
\hline Khulna & $8.0 \%$ & $3.1 \%$ & $6.1 \%$ & & \\
\hline Rajshahi & $6.3 \%$ & $2.5 \%$ & $5.0 \%$ & & \\
\hline Rangpur & $5.9 \%$ & $1.7 \%$ & $4.0 \%$ & & \\
\hline Sylhet & $4.6 \%$ & $1.7 \%$ & $4.1 \%$ & & \\
\hline \multicolumn{6}{|l|}{ Type of Residence } \\
\hline Urban & $20.3 \%$ & $6.9 \%$ & $14.1 \%$ & 13.359 & $0.001^{*}$ \\
\hline Rural & $26.9 \%$ & $10.2 \%$ & $21.5 \%$ & & \\
\hline \multicolumn{6}{|c|}{ Sex of Household Head } \\
\hline Male & $41.9 \%$ & $15.6 \%$ & $32.1 \%$ & 12.201 & $0.002^{*}$ \\
\hline Female & $5.4 \%$ & $1.5 \%$ & $3.6 \%$ & & \\
\hline
\end{tabular}

*Significant at $p<0.05$

likely to be in High score or moderate score when compared to Sylhet. Age, although not significantly correlated as an independent variable, women in the age ranges 15-19 and 20-24 were significantly less likely to be the higher score group as compared with the low score group of HIV knowledge, compared to women from 44 to 49 years age range. This provides strategic direction as to the focus of prevention strategies for HIV. 
Table 4 Factors influencing HIV knowledge among women ageing between 15 and 49 in Bangladesh. 2011

\begin{tabular}{|c|c|c|c|c|c|c|c|}
\hline & & \multirow[t]{2}{*}{ B } & \multirow[t]{2}{*}{ S.E. } & \multirow[t]{2}{*}{ Sig. } & \multirow[t]{2}{*}{ OR } & \multicolumn{2}{|c|}{$95 \% \mathrm{Cl}$} \\
\hline & & & & & & Lower & Upper \\
\hline \multirow[t]{34}{*}{ High Score } & Intercept & 0.986 & 0.256 & 0.000 & & & \\
\hline & Age & & & & & & \\
\hline & $15-19$ years & -0.276 & 0.097 & 0.004 & 0.759 & 0.627 & 0.917 \\
\hline & $20-24$ years & -0.197 & 0.087 & 0.024 & 0.821 & 0.693 & 0.974 \\
\hline & $25-29$ years & -0.120 & 0.086 & 0.165 & 0.887 & 0.749 & 1.051 \\
\hline & 30-34 years & 0.041 & 0.089 & 0.645 & 1.042 & 0.875 & 1.241 \\
\hline & $35-39$ years & 0.041 & 0.092 & 0.654 & 1.042 & 0.870 & 1.248 \\
\hline & 40-44 years & 0.030 & 0.095 & 0.749 & 1.031 & 0.856 & 1.242 \\
\hline & $45-49$ years & $0^{b}$ & & & & & \\
\hline & Residence & & & & & & \\
\hline & Urban & 0.016 & 0.047 & 0.728 & 1.016 & 0.927 & 1.114 \\
\hline & Rural & $0^{b}$ & & & & & \\
\hline & Highest education & & & & & & \\
\hline & No education & -0.806 & 0.089 & 0.000 & 0.447 & 0.375 & 0.531 \\
\hline & Primary education & -0.513 & 0.077 & 0.000 & 0.599 & 0.514 & 0.697 \\
\hline & Secondary education & -0.242 & 0.070 & 0.001 & 0.785 & 0.684 & 0.901 \\
\hline & Higher education & $0^{b}$ & & & & & \\
\hline & Sex of household head & & & & & & \\
\hline & Male & -0.150 & 0.066 & 0.024 & 0.861 & 0.756 & 0.980 \\
\hline & Female & $0^{b}$ & & & & & \\
\hline & Wealth Index & & & & & & \\
\hline & Poorest & -0.105 & 0.084 & 0.212 & 0.901 & 0.764 & 1.061 \\
\hline & Poor & -0.270 & 0.075 & 0.000 & 0.763 & 0.659 & 0.884 \\
\hline & Middle & -0.061 & 0.068 & 0.369 & 0.941 & 0.824 & 1.075 \\
\hline & Rich & -0.053 & 0.059 & 0.371 & 0.949 & 0.845 & 1.065 \\
\hline & Richest & $0^{b}$ & & & & & \\
\hline & Region & & & & & & \\
\hline & Barisal & 0.539 & 0.087 & 0.000 & 1.713 & 1.444 & 2.033 \\
\hline & Chittagong & -0.026 & 0.079 & 0.746 & 0.975 & 0.834 & 1.139 \\
\hline & Dhaka & 0.083 & 0.078 & 0.284 & 1.087 & 0.933 & 1.265 \\
\hline & Khulna & 0.166 & 0.079 & 0.036 & 1.180 & 1.011 & 1.379 \\
\hline & Rajshahi & 0.113 & 0.083 & 0.171 & 1.120 & 0.952 & 1.318 \\
\hline & Rangpur & 0.297 & 0.086 & 0.001 & 1.346 & 1.136 & 1.595 \\
\hline & Sylhet & $0^{b}$ & & & & & \\
\hline \multirow[t]{8}{*}{ Moderate Score } & Intercept & -1.189 & 0.364 & 0.001 & & & \\
\hline & Age & & & & & & \\
\hline & $15-19$ years & -0.222 & 0.127 & 0.081 & 0.801 & 0.625 & 1.028 \\
\hline & 20-24 years & -0.144 & 0.113 & 0.202 & 0.866 & 0.693 & 1.081 \\
\hline & $25-29$ years & -0.051 & 0.112 & 0.651 & 0.951 & 0.764 & 1.184 \\
\hline & 30-34 years & 0.042 & 0.116 & 0.714 & 1.043 & 0.831 & 1.309 \\
\hline & $35-39$ years & -0.031 & 0.120 & 0.795 & 0.969 & 0.765 & 1.227 \\
\hline & 40-44 years & 0.036 & 0.123 & 0.771 & 1.037 & 0.815 & 1.319 \\
\hline
\end{tabular}


Table 4 Factors influencing HIV knowledge among women ageing between 15 and 49 in Bangladesh. 2011 (Continued)

\begin{tabular}{|c|c|c|c|c|c|c|}
\hline $45-49$ years & $0^{b}$ & & & & & \\
\hline \multicolumn{7}{|l|}{ Residence } \\
\hline Urban & -0.037 & 0.062 & 0.549 & 0.964 & 0.853 & 1.088 \\
\hline Rural & $0^{\mathrm{b}}$ & & & & & \\
\hline \multicolumn{7}{|l|}{ Highest education } \\
\hline No education & -0.106 & 0.119 & 0.374 & 0.900 & 0.713 & 1.136 \\
\hline Primary education & -0.008 & 0.107 & 0.943 & 0.992 & 0.805 & 1.223 \\
\hline Secondary education & 0.111 & 0.098 & 0.255 & 1.118 & 0.923 & 1.354 \\
\hline Higher education & $0^{\mathrm{b}}$ & & & & & \\
\hline \multicolumn{7}{|l|}{ Sex of household head } \\
\hline Male & 0.157 & 0.093 & 0.090 & 1.170 & 0.976 & 1.402 \\
\hline Female & $0^{\mathrm{b}}$ & & & & & \\
\hline \multicolumn{7}{|l|}{ Wealth Index } \\
\hline Poorest & -0.005 & 0.107 & 0.961 & 0.995 & 0.806 & 1.227 \\
\hline Poor & -0.289 & 0.099 & 0.004 & 0.749 & 0.616 & 0.910 \\
\hline Middle & -0.001 & 0.088 & 0.988 & 0.999 & 0.841 & 1.187 \\
\hline Rich & -0.135 & 0.078 & 0.086 & 0.874 & 0.750 & 1.019 \\
\hline Richest & $0^{b}$ & & & & & \\
\hline \multicolumn{7}{|l|}{ Region } \\
\hline Barisal & 0.275 & 0.118 & 0.019 & 1.317 & 1.045 & 1.659 \\
\hline Chittagong & 0.067 & 0.105 & 0.526 & 1.069 & 0.870 & 1.314 \\
\hline Dhaka & 0.220 & 0.101 & 0.030 & 1.246 & 1.021 & 1.519 \\
\hline Khulna & 0.235 & 0.104 & 0.024 & 1.265 & 1.032 & 1.550 \\
\hline Rajshahi & 0.209 & 0.108 & 0.054 & 1.233 & 0.997 & 1.525 \\
\hline Rangpur & 0.048 & 0.118 & 0.684 & 1.049 & 0.833 & 1.322 \\
\hline Sylhet & $0^{\mathrm{b}}$ & & & & & \\
\hline
\end{tabular}

Reference category is High Score. $0^{\mathrm{b}}$ is reference category * Significant at $p<0.05$ OR Odds ratio

\section{Discussion}

Despite its current low rate, the risk of further expansion of HIV remains high in Bangladesh due to widespread prevalence of the risk factors [17, 22, 23, 32]. Special policy attention will be required to make proper use this opportunity to curb further spread in the country. To facilitate the task, a key step will be conducting large-scale epidemiological studies exploring the direct and remotely associated risk factors especially peoples' awareness regarding the causes and consequences of the epidemic. Prior studies have demonstrated that prevalence is significantly higher among people who are unaware of the potential routes of transmission [33, 34]. From this perspective, developing a profound understanding on the demographic and sociocultural determinants of peoples' awareness can set the avenue for evidenced based and effective policy making. To the best of our knowledge, this is the first population-based study on Bangladesh to contribute to the literature from this context. In light of the findings of this study, women's level of HIV knowledge in
Bangladesh is noticeably low. Though most women were aware the major routes of transmission including unsafe blood transfusion and unsterilized needle utilization, there seems to be an overestimation of participants' perception of risk of transmission through mosquito bites and food sharing with someone who has HIV/AIDS. Respectively 47.3 and $55.6 \%$ women identified these two as risk factors for transmission of HIV. Results imply the necessity for a greater emphasis on clarifying the confusions regarding mode of transmission.

Previous studies have identified education as a 'social vaccine' against HIV/AIDS and these findings are corroborated with the findings of the current study were education was found to be significantly correlated with the level of HIV knowledge [31]. In the same vein as that of UNICEF, women's education has wider repercussions and as per the current study education increases the chances of having higher HIV knowledge.

Contrary to the expectation, household wealth status was not significantly associated with HIV knowledge 
status. Although the four wealth quartiles, ranging from poorest to richer were less likely to be in the high score group of HIV knowledge than for those who were in the richest quartile, the findings were not statistically significant. The belief that economic solvency ensures access to basic necessities such as proper living condition, education, healthcare services which provides the condition for effective health communication and knowledge acquirement may not be directly playing a role in HIV knowledge, however the indirect impact through education or gender inequity might be of import. Though the country has experienced a substantial rise in per capita income in recent years, $31.5 \%$ of the population lives below national poverty line as per Asian Development Bank, Basic Statistics 2016, especially among women, which reduces women's capacity to seek for health services. Women from male-headed households having lower HIV knowledge further supports the fact that gender inequity may be playing a role in acquisition of HIV knowledge. In a society fraught with gender discrimination it is assumable that women in male-headed families enjoy less than necessary freedom to engage in adult health education or alike activities that do not align with the concerns of the household head. Such barriers are hard to address by policy making and require change in public attitudes about the value systems in societies. Previous studies have also stressed the importance of gender inequality as factors to be incorporated in 'positive prevention' strategies for HIV/AIDS [35].

\section{Strength and limitations}

Our study included a relatively large dataset, was representative of the general population and examined the impact of some very crucial determinants of HIV knowledge. The study was the first of this kind in the context of Bangladesh and invites more detailed and large-scale studies including more culture related determinants. Despite that, our study had few important shortcomings. Utilization of secondary data meant that we had no control over the selection of variables, quality of data, and the measurement of indicators. Moreover, the survey was conducted in 2011; therefore, the current level of HIV awareness may not coincide with our findings.

\section{Conclusion}

This study examined the extent and determinants of HIV knowledge among sexually active women in Bangladesh. The findings indicate that HIV prevention programs have a lot to improve in creating general awareness and clarifying misconceptions regarding mode of transmission of the disease. Education and sex of the household head were significantly correlated with the knowledge of HIV and reaffirms the findings from previous studies as well as indicates the import of their incorporation in the HIV prevention strategies. In the same vein, reducing gender inequality through education can be a viable option for increasing HIV knowledge status. Though being of rural of urban origin showed no significant correlation with HIV knowledge status, rural women are less likely to enjoy the healthcare and counseling facilities compared to their urban counterparts and remain somewhat isolated from the service network. People are more unlikely to seek counseling and treatment for STDs. Social workers have to devise innovative ways to grow trust among people in the services providers and encourage service utilization.

\section{Acknowledgments \\ The authors thank the MEASURE DHS project for their support and for free access to the original data.}

\section{Funding}

The authors have no support or funding to report.

\section{Availability of data and materials}

Data for this study were sourced from the sixth round of Bangladesh Demographic and Health survey (BDHS) and available here: http:// dhsprogram.com/pubs/pdf/fr265/fr265.pdf.

\section{Authors' contributions}

SY and GB and GD participated in the conception and design of the study, data cleaning and analysis, results interpretation, and drafting and revision of the manuscript. SY, GD and SV and ME participated in review of statistical methods, results interpretation, and revision of the manuscript. All authors read and approved the final manuscript.

\section{Competing interests}

The authors declare that they have no competing interests.

\section{Consent for publication}

No consent to publish was needed for this study as we did not use any details, images or videos related to individual participants. In addition data used is available in the public domain.

Ethics approval and consent to participate

Ethics approval for this study was not required since the data is secondary and is available in the public domain. More details regarding DHS data and ethical standards are available at: http://goo.gl/ny8T6X.

\section{Author details}

${ }^{1}$ School of International Development and Global Studies, Faculty of Social Sciences, University of Ottawa, Ottawa, ON, Canada. ${ }^{2}$ School of Medicine and Health Management, Tongji Medical College, Huazhong University of Science and Technology, Wuhan, Hubei, China. ${ }^{3}$ Faculty of Health, York University, Toronto, ON, Canada. ${ }^{4}$ Interdisciplinary School of Health Sciences, Faculty of Health Sciences, University of Ottawa, Ottawa, ON K1N 6N5, Canada. ${ }^{5}$ The Women's Health and Action Research Centre, Benin City, Nigeria.

Received: 10 February 2016 Accepted: 13 August 2016

Published online: 17 August 2016

\section{References}

1. Glynn JR, Caral M, Auvert B, Kahindo M, Chege J, et al. Why do young women have a much higher prevalence of HIV than young men? A study in Kisumu, Kenya and Ndola, Zambia. AIDS. 2001;15 Suppl 4:S51-60.

2. Shannon K, Leiter K, Phaladze N, Hlanze Z, Tsai AC, Heisler M, et al. Gender inequity norms are associated with increased male-perpetrated rape and sexual risks for HIV infection in Botswana and Swaziland. PLoS One. 2012; 7(1):e28739.

3. Dunkle KL, Jewkes RK, Brown HC, Gray GE, Mclntryre JA, et al. Gender-based violence, relationship power, and risk of HIV infection in women attending antenatal clinics in South Africa. Lancet. 2004;363:1415-21. 
4. Shannon K, Kerr T, Strathdee SA, Shoveller J, Montaner JS, et al. Prevalence and structural correlates of gender-based violence in a prospective cohort of female sex workers. BMJ. 2009;339:b2939.

5. Gari S, Malungo JRS, Martin-Hilber A, Musheke M, Schindler C, Merten S. HIV testing and tolerance to gender based violence: a cross-sectional study in Zambia. PLoS One. 2013:8(8):e71922.

6. Carael M, Marais H, Polsky J, Mendoza A. Is there a gender gap in the HIV response? Evaluating national HIV responses from the United Nations General Assembly Special Session on HIV/AIDS country reports. J Acquir Immune Defic Syndr. 2009;52 Suppl 2:S111-8.

7. Pellowski JA, Kalichman SC, Matthews KA, Adler N. A pandemic of the poor: social disadvantage and the U.S. HIV epidemic. Am Psychol. 2013;68(4):197-209.

8. Turmen T. Gender and HIV/AIDS. Int J Gynecol Obstet. 2003;82(3):411-8.

9. Shawn FD, Glenn F. Trends in Global Gender Inequality (Forthcoming, Social Forces). Soc Forces. 2010;88(5):1941-68.

10. Lacey E, Walters S. Continuing inequality: gender and social class influences on self perceived health after a heart attack. J Epidemiol Community Health. 2003;57(8):622-7.

11. Powell HL, Segrin C. The effect of family and peer communication on college students' communication with dating partners about HIV and AIDS. Health Commun. 2004;16(4):427-49.

12. Wolf RC, Pulerwitz J. The influence of peer versus adult communication on AIDS-protective behaviors among Ghanaian youth. J Health Commun. 2003; 8(5):463-74

13. Ackerson LK, Ramanadhan S, Arya M, Viswanath K. Social disparities, communication inequalities, and HIV/AIDS-related knowledge and attitudes in India. AIDS Behav. 2012;16(7):2072-81.

14. Eric R. The positive role of social networks and social networking technology in the condom-using behaviors of homeless young people. Public Health Rep. 2010;125(4):588-95.

15. Amirkhanian YA, Kelly JA, Takacs J, McAuliffe TL, Kuznetsova AV, Toth TP, e al. Effects of a social network HIV/STD prevention intervention for MSM in Russia and Hungary: a randomized controlled trial. AIDS. 2015;29(5):583-93.

16. Youm Y, Laumann EO. Social network effects on the transmission of sexually transmitted diseases. Sex Transm Dis. 2002;29(11):689-97.

17. Mosharaf H, Kulanthayan KCM, Sherina MS, Hayati KS, Rafiqul I. Knowledge and awareness about STDs among women in Bangladesh. BMC Public Health. 2014;14:775

18. Azim T, Rahman M, Alam M, Chowdhury I, Khan R, et al. Bangladesh moves from being a low-prevalence nation for HIV to one with a concentrated epidemic in injecting drug users. International journal of STD \& AIDS. 2008; 19:327-31. doi:10.1258/ijsa.2007.007269.

19. Tasnim A, Sharful IK, Fariha H, Nafisa LH, Lars H, Moshtaq P. HIV and AIDS in Bangladesh. J Health Popul Nutr. 2008:26(3):311-24.

20. Gibney L, Saquib N, Metzger J. Behavioral risk factors for STD/HIV transmission in Bangladesh's trucking industry. Soc Sci Med. 2003;56(7): 1411-24.

21. Azim T, Bogaerts J, Yirrell DL, Banerjea AC, Sarker MS, Ahmed G, et al. Injecting drug users in Bangladesh: prevalence of syphilis, hepatitis, HIV and HIV subtypes. AIDS. 2002;16(1):121-3.

22. Azim T, Chowdhury El, Reza M, Faruque MO, Ahmed G, Khan R. Prevalence of infections, HIV risk behaviors and factors associated with HIV infection among male injecting drug users attending a needle/syringe exchange program in Dhaka, Bangladesh. Subst Use Misuse. 2008;43(14):2124-44.

23. Sarkar K, Bal B, Mukherjee R, Chakraborty S, Niyogi SK, Saha MK. Epidemic of HIV coupled with hepatitis C virus among injecting drug users of Himalayan West Bengal, Eastern India, Bordering Nepal, Bhutan, and Bangladesh. Subst Use Misuse. 2006;41(3):341-52.

24. Pascoe SJS, Langhaug LF, Mavhu W, Hargreaves J, Jaffar S, Hayes R, et al. Poverty, Food Insufficiency and HIV Infection and Sexual Behaviour among Young Rural Zimbabwean Women. PLoS One. 2015;10(1):e0115290.

25. Piot P, Greener R, Russell S. Squaring the circle: AIDS, poverty, and human development. PLoS Med. 2007:4(10):e314.

26. Janet MT, Cassio L, Richard MG. Poverty and health. JAMA. 2007;298(16): 1968.

27. Jennifer S, Paul F. Treating HIV in resource-poor settings. JAMA. 2002; 288(13):1652-3.

28. Varni SE, Miller CT, Solomon SE. Sexual behavior as a function of stigma and coping with stigma among people with HIV/AIDS in rural New England. AIDS Behav. 2012;16(8):2330-9.
29. Anish PM, Jennifer NS, Vishal AP, Robert HR, Daniel O, Greg S, et al. Stigma in the HIV/AIDS epidemic: a review of the literature and recommendations for the way forward. AIDS. 2008;22 Suppl 2:S67-79.

30. Ronald OV. HIV/AIDS Stigma: an impediment to public health. Am J Public Health. 2002;92(3):341-2

31. Mwamwenda TS. Education level and HIV/AIDS knowledge in Kenya. J AIDS and HIV Res. 2014;6(2):28-32.

32. Khosla N. HIV/AIDS Interventions in Bangladesh: what can application of a social exclusion framework tell us? J Health Popul Nutr. 2009;27(4):587-97.

33. Gambo A, Mukhtar M, Ahmed S, Prosanta M, Man C, Alash'le A, et al. HIV infection awareness and willingness to participate in future HIV vaccine trials across different risk groups in Abuja, Nigeria. AIDS Care. 2010;22(10):1277-84.

34. Nana NA, Robert HS. Knowledge and awareness of HIV/AIDS among high school girls in Ghana. HIV AIDS (Auckl). 2013;5:137-44.

35. Fladseth K, Gafos M, Newell ML, McGrath N. The impact of gender norms on condom use among HIV-Positive adults in KwaZulu-Natal, South Africa. PLoS One. 2015;10:e0122671. http://dx.doi.org/10.1371/journal.pone.0122671.

\section{Submit your next manuscript to BioMed Central and we will help you at every step:}

- We accept pre-submission inquiries

- Our selector tool helps you to find the most relevant journal

- We provide round the clock customer support

- Convenient online submission

- Thorough peer review

- Inclusion in PubMed and all major indexing services

- Maximum visibility for your research

Submit your manuscript at www.biomedcentral.com/submit
) Biomed Central 